\title{
A market assessment for modern cooking in Malawi
}

\author{
Will Coley \\ Electronic \& Electrical \\ Engineering, \\ University of Strathclyde, University of Strathclyde, \\ Glasgow, U.K. \\ william.coley@strath.ac.uk aran.eales@strath.ac.uk
}

\author{
Damien Frame \\ Electronic \& Electrical \\ Engineering, \\ University of Strathclyde, \\ Glasgow, U.K. \\ damien.frame@strath.ac.uk
}

\author{
Stuart Galloway \\ Electronic \& Electrical \\ Engineering, \\ University of Strathclyde, \\ Glasgow, U.K. \\ stuart.galloway.@strath.ac.uk
}

\author{
Lloyd Archer \\ Sustainable Energy \\ Management Unit, \\ United Purpose, \\ Lilongwe, Malawi \\ lloyd.archer@united- \\ purpose.org
}

\begin{abstract}
This paper presents the findings from a study which used household surveys and expert interviews to investigate cooking practices and understand the barriers and opportunities to the growth of the modern cooking sector in Malawi. The findings from expert interviews highlight barriers to electric and LPG cooking around the weakness of existing infrastructure, lack of consumer willingness and ability to pay and resistance to the adoption of modern cooking devices. The greatest opportunity for electric cooking is in urban areas and on mini-grids, while LPG is also most viable in urban areas, however knowledge and infrastructure gaps need to be narrowed to facilitate growth. An analysis of household surveys in urban, peri-urban and rural areas, using data from "indicative cooking diaries", demonstrates the diversity of cooking practices in Malawian households by showing what, how, and with what, dishes are cooked. It is demonstrated that there is a latent demand for modern cooking in Malawi. Targeted research is needed to test modern cooking devices' ability to cook Malawian dishes in ways which are acceptable to Malawian people, in order to effectively accelerate a transition towards modern cooking in Malawi and address the negative health and environmental impacts of biomass cooking.
\end{abstract}

Keywords—modern cooking, Malawi, market assessment

\section{INTRODUCTION}

Almost three billion people currently lack access to clean cooking [1], instead using traditional fuels such as firewood and charcoal. This practice, most prevalent in Asia and Africa, causes environmental damage through climate change, deforestation, droughts and flooding [2], and leads to as many as 4 million premature deaths every year due to illnesses linked to indoor air pollution [3]. While Asian countries have shown a slow but steady decline in the total number without clean cooking access over the last 20 years, the opposite is true for sub-Saharan Africa where almost a third of the global total are now situated [1].

Such a trend is evident in Malawi, one of the world's poorest countries with the third lowest per capita GDP [4] and fourth highest proportion of people living on less than $\$ 1.90$ per day [5]. $98 \%$ of the population rely on biomass fuels such as firewood and charcoal for cooking [6]. This comes in a context where access to electricity is just $13 \%$, concentrated almost exclusively in urban areas, while frequent blackouts due to load shedding make electricity unreliable in areas which do have access. The availability and use of other clean fuels such as liquid petroleum gas (LPG), ethanol and biogas is negligible [6].
A small number of recent studies have sought to understand the feasibility of different modern cooking fuels in Malawi, such as LPG [7] and ethanol [8]. These studies showed that electricity is likely to be the cheapest cooking fuel in grid connected areas, echoing similar findings from studies up to 25 years ago [9]. However, such efforts focus on the technical and economic feasibility of such fuels and devices, neglecting that "cooking practices are heavily dependent on culture, cuisine, household dynamics, as well as the availability of socially acceptable and affordable fuels and technologies" [1, p. 55].

As such, national policies in Malawi focus almost exclusively on the widespread adoption of improved biomass cookstoves (locally called "chitetezo mbaula" [10]), aiming to achieve a target of 2 million stoves in use by the end of 2020 [11], and 5 million by the end of 2030 [12]. Across three relevant policies (National Energy Policy [11], National Charcoal Strategy [13] and Malawi Renewable Energy Strategy [14]) modern cooking is only briefly mentioned. While a strong focus is given to increasing access to electricity, electric cooking is rarely mentioned and LPG is considered the most viable alternative to biomass cooking in the medium term. However, any comments to this effect are supplemented by acknowledgement that currently costs are high, demand is low and infrastructure is limited in its ability to support a national scale-up of LPG cooking.

Modern Energy Cooking Services (MECS) is a UKAid funded programme with the overarching objective to "rapidly accelerate the transition from biomass to clean cooking on a global scale" [15]. This paper outlines the key findings of a market assessment for modern cooking in Malawi; "modern" is here used to distinguish non-traditional energy sources such as electricity and LPG, from "cleaner" or "improved" cooking fuels or devices, e.g. briquettes and improved biomass cookstoves. This study helps to better understand the cooking ecosystem in Malawi and follows a framework process conducted in previous studies in neighbouring countries (Tanzania [16] and Zambia [17]) which formed the foundations of the MECS programme. The paper presents both a top-down perspective through interactions with experts (private, public and third sector actors) from Malawi's clean cooking sector, and a bottom-up perspective through interactions at a household level. The findings are intended to inform and stimulate the modern cooking sector in Malawi while providing recommendations for an accelerated transition towards modern cooking fuels and technologies. 


\section{Methodology}

This market assessment for modern cooking used a mixed methods approach, gathering primary data on cooking in Malawi from both top-down (policy and practitioner level) and bottomup (household level) perspectives. The methodology built upon those used by the MECS programme in other East African countries [16] [17] and other similar market assessment methodologies [18] [19]. Activities were facilitated by local partners United Purpose and Community Energy Malawi.

\section{A. Policy and practitioner level data collection}

To lay the foundations for interviews with clean cooking experts (private, public and third sector actors) the main policies relevant to cooking in Malawi were reviewed to understand the focus of national efforts to reduce biomass fuel use in cooking [11] [13] [14]. This was followed by a short online survey sent out to contacts in several energy and cooking networks in Malawi including members of the National Cookstove Steering Committee (NCSC) [20]. The survey covered topics including: cooking practices; drivers towards clean cooking; past, ongoing and planned interventions on modern cooking; and barriers and opportunities for modern cooking in Malawi. The survey received 15 responses including private sector actors, practitioners, academics and government officials, and was used to invite participants for semi-structured interviews.

Seven interviews with NCSC members (three from international NGOs, three from local NGOs and one academic from a Malawian university) were completed under a topic guide developed using the findings from the policy review and online survey, and referring to the "policy/markets review framework" question list used in previous MECS studies [16] [17]. The interviews covered: prior work and knowledge regarding modern cooking; opportunities, barriers and viability of modern cooking; and delivery methods for modern cooking in Malawi.

\section{B. Household level data collection}

Data collection at the household level was conducted using household surveys and focus groups. Households were surveyed in three locations targeting different population groups which are described as "urban", "peri-urban" and "rural" (Fig. 1). Using knowledge of local partners, sample areas were selected as follows: urban - households in affluent areas of Lilongwe; periurban - less affluent households towards the outskirts of Lilongwe; rural - households in a poor, remote community.

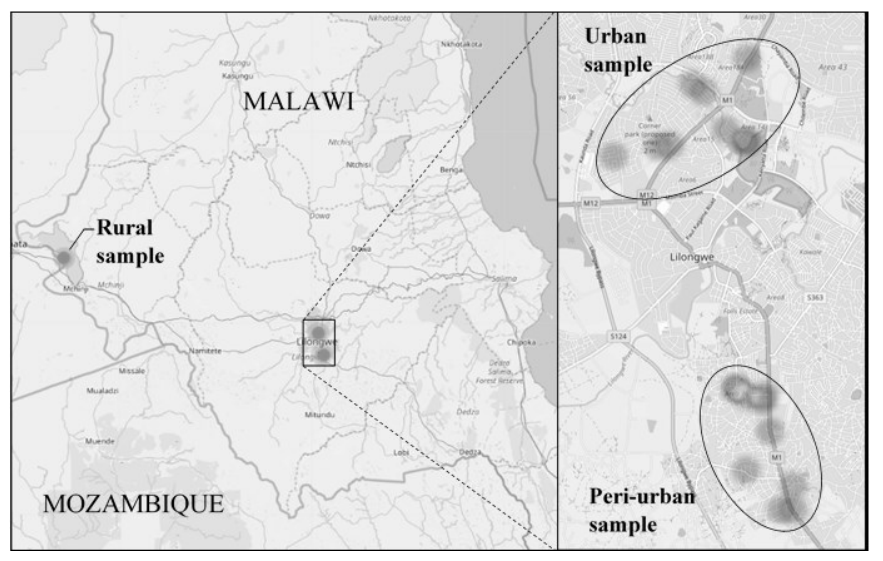

Fig. 1. Map of sample area locations
Convenience sampling was used in all locations, with urban and peri-urban participants being surveyed in their homes, while rural participants were surveyed in the village church. The survey targeted the self-identified "main household cook", and as such the sample does not necessarily always represent the homeowner, or even a family member as some of the urban and peri-urban participants were maids who are responsible for most of the household cooking. Also, the survey did not specifically target women, however most respondents were female. In total 57 participants were surveyed (see Table I for a breakdown).

TABLE I. SAMPLE SIZE (BY LOCATION AND GENDER)

\begin{tabular}{|l|c|c|c|c|}
\cline { 2 - 5 } \multicolumn{1}{c|}{} & \multicolumn{4}{c|}{ Location } \\
\hline Gender & All & Urban & Peri & Rural \\
\hline All & 57 & 14 & 14 & 29 \\
\hline Male & 5 & 3 & 2 & 0 \\
\hline Female & 52 & 11 & 12 & 29 \\
\hline
\end{tabular}

The survey was developed using MECS methodologies [16] [17] [21] and household energy baselining surveys from an ongoing project [22] and administered using the kobocollect mobile application [23]. Pre-testing led to revisions altering multiple-choice options including cooking devices and foods which were most relevant to the Malawian context. The duration of the survey was 15-20 minutes; prioritising closed questions with multiple choice answers, with focus groups to be used to gather less structured information. The household survey included three sections; participant and household background information; general cooking information including cooking expenditure, kitchen location and what fuel or device is used to cook; and the construction of an indicative cooking diary. This final section used a novel, survey based technique to collect detailed information on the dishes cooked, cooking method and device used to cook on a typical weekday and weekend day; similar to information gathered by more labour intensive methodologies [18] [21] in other MECS countries [16] [17]. The survey was accompanied by a sheet showing images of the cooking devices, to ensure that the correct options were selected.

A focus group was also conducted in the rural location. This was attended by 30 community members and included a discussion of initial findings from the household surveys, and a participatory exercise to generate and rank positive and negative aspects of using firewood and charcoal for cooking.

\section{FINDINGS}

This section presents findings from the analysis of data collected through interactions with clean cooking experts in Malawi, followed by data collected at a household level.

\section{A. Interactions with clean cooking experts}

\section{1) Drivers towards clean cooking in Malawi}

\section{a) Main driver: Tackling deforestation}

Almost all respondents to the online survey and expert interviews indicated that deforestation was the most important driver for transitioning to modern cooking in Malawi. The mentioned impacts of which were climate change, scarcity of wood-fuel and damage to agricultural land. Most interviewees highlighted the findings of the most extensive project in recent years seeking to understand and tackle deforestation, "Protecting 
Ecosystems and Restoring Forests in Malawi” (PERFORM) [24], which revealed urban demand for wood fuels and charcoal as a key cause of deforestation in Malawi. A report produced by PERFORM [7] highlighted that LPG in particular has a key role in reducing biomass fuel use and thus deforestation, citing its efficiency as a cooking fuel and relatively stable price compared with charcoal and electricity.

\section{b) Other drivers: Public health and poverty alleviation}

Experts also highlighted the need to address public health issues caused by smoke produced by cooking with biomass. Another factor mentioned was poverty alleviation (particularly in rural areas), through reducing expenditure on fuels by encouraging the use of more efficient biomass stoves and fostering economic development in rural communities through creating businesses which manufacture improved stoves.

\section{2) Barriers and opportunities for modern cooking}

Four key barrier types which broadly sit across both LPG and electric cooking were highlighted; weakness/lack of infrastructure, unwillingness/inability to pay and socio-cultural resistance to device adoption. A summary of these barriers is shown in Table II.
Considering these barriers, experts were also asked to highlight the areas of opportunity for modern cooking in Malawi. These are broadly geographical (electric cooking in urban areas and on mini-grids, LPG cooking in urban areas) as well as behavioural in nature (electric cooking is aspirational, LPG cooking has highly desirable attributes). The short-medium term opportunities are summarised in Table III.

Local prices for biomass, LPG and electric cooking devices were gathered (see Table IV, exchange rate: $1 \mathrm{USD}=737 \mathrm{MWK}$ as of $30^{\text {th }}$ April 2020). The most basic hotplate costs upwards of 7,500 MWK while charcoal stoves are widely available for around 2,500 MWK and improved firewood stoves cost 1,000 MWK. More efficient cooking practises which could immediately reduce fuel expenditure at little or no cost, such as using lids or soaking beans, are scarcely practised. In addition, the use of rice cookers and pressure cookers (electric or traditional) is negligible. The cheapest rice cookers are as expensive as the most expensive electric hotplates $(20,000$ MWK) and electric pressure cookers are similarly priced to microwaves at over 60,000 MWK.

TABLE II. SUMMARY OF BARRIERS TO LPG AND ELECTRIC COOKING IN MALAWI

\begin{tabular}{|c|l|l|}
\cline { 2 - 3 } \multicolumn{1}{c|}{} & \multicolumn{1}{c|}{ Summary of barrier } \\
\hline Barrier type & \multicolumn{1}{|c|}{ Electric cooking } & \multicolumn{1}{c|}{ LPG cooking } \\
\hline $\begin{array}{c}\text { Weakness/lack of } \\
\text { infrastructure }\end{array}$ & $\begin{array}{l}\text { Low levels of electricity access outside urban areas and } \\
\text { unreliable supply in grid connected areas puts consumers off } \\
\text { cooking with electricity. Although positive change is likely in 5- } \\
10 \text { years, in the short-medium term the high electrical demand } \\
\text { requirements of electric cooking are likely to add further } \\
\text { pressure to Malawi's already overstressed grid. }\end{array}$ & $\begin{array}{l}\text { Currently there is a very low demand for LPG in Malawi and thus } \\
\text { the existing market lacks economies of scale. A scarcity of LPG } \\
\text { suppliers makes fuel replenishment inconvenient for those who do } \\
\text { want to use it who must replace or refill large and heavy gas } \\
\text { cylinders themselves at scattered locations. Many rural areas are } \\
\text { almost unserviceable due to poor roads. }\end{array}$ \\
\hline $\begin{array}{c}\text { Unwillingness/ } \\
\text { inability to pay }\end{array}$ & $\begin{array}{l}\text { High upfront cost of electric cooking devices and perception } \\
\text { that energy is expensive relative to charcoal makes electric } \\
\text { cooking unaffordable for many and puts off some consumers who } \\
\text { could afford it. }\end{array}$ & $\begin{array}{l}\text { Relative to charcoal and electricity, cooking with LPG requires } \\
\text { high upfront costs to pay for devices and large payments for fuel } \\
\text { in order to refill or replace cylinders. Such lump sums are } \\
\text { unaffordable for most Malawian households. }\end{array}$ \\
\hline $\begin{array}{c}\text { Socio-cultural } \\
\text { resistance to device } \\
\text { adoption }\end{array}$ & $\begin{array}{l}\text { Lack of practice, understanding and awareness of efficient } \\
\text { cooking techniques (e.g. using lids and soaking beans) and } \\
\text { devices (e.g. pressure cookers) make low powered, efficient } \\
\text { electric cooking devices unfamiliar to most Malawians. }\end{array}$ & $\begin{array}{l}\text { Widespread perception that cooking with LPG is dangerous } \\
\text { makes Malawians from all levels of society hesitant to adopt LPG as } \\
\text { a cooking fuel. }\end{array}$ \\
\hline
\end{tabular}

TABLE III. SUMMARY OF OPPORTUNITIES FOR LPG AND ELECTRIC COOKING IN MALAWI

\begin{tabular}{|c|l|l|}
\cline { 2 - 3 } \multicolumn{1}{c|}{} & \multicolumn{1}{c|}{ Summary of opportunity (short-medium term) } \\
\hline Opportunity type & \multicolumn{1}{c|}{ Electric cooking } & \multicolumn{1}{c|}{ LPG cooking } \\
\hline Geographical & $\begin{array}{l}\text { Urban areas and mini-grids are likely to present the most } \\
\text { immediate opportunity for electric cooking. } \\
\text { Urban: high incomes and existing practice of electric cooking. } \\
\text { Minigrids: reliable electricity supply, potential for pay-as-you- } \\
\text { cook business model and high levels of community engagement. }\end{array}$ & $\begin{array}{l}\text { Urban areas are most suited to LPG cooking as this is where there is } \\
\text { existing demand (although currently very limited). This area will } \\
\text { have the lowest distribution costs, highest household incomes and } \\
\text { is perhaps most likely to be receptive to awareness campaigns } \\
\text { around gas safety. }\end{array}$ \\
\hline Behavioral & $\begin{array}{l}\text { Electric cooking is aspirational for many Malawians. Basic } \\
\text { devices (e.g. hotplates, kettles) are well understood (though low } \\
\text { power, efficient devices (e.g. EPCs) are not). The population } \\
\text { cooking with electricity grew when the grid was reliable. }\end{array}$ & $\begin{array}{l}\text { Cooking with LPG is very similar to cooking with firewood and } \\
\text { charcoal, so requires little behavior change in terms of cooking } \\
\text { technique. Also, it is fast (lighting and cooking), easy to control, } \\
\text { smokeless and odorless, all highly desirable attributes. }\end{array}$ \\
\hline
\end{tabular}

TABLE IV. COSTS OF COOKING DEVICES (PRICES IN MWK)

\begin{tabular}{|c|c|c|c|c|c|c|c|c|c|}
\hline \multicolumn{2}{|l|}{ Biomass } & \multicolumn{2}{|l|}{ LPG } & \multicolumn{6}{|l|}{ Electric } \\
\hline $\begin{array}{l}\text { Firewood - } \\
3 \text { stone fire }\end{array}$ & Free & $\begin{array}{l}\text { Cylinder } \\
\text { burner (3kg) }\end{array}$ & 30000 & Hotplate & $7500-20000$ & Rice cooker & $20000-48000$ & $\begin{array}{l}\text { Pressure } \\
\text { cooker }\end{array}$ & $67000-95000$ \\
\hline $\begin{array}{l}\text { Firewood - } \\
\text { improved stove }\end{array}$ & 1000 & $\begin{array}{l}\text { Portable } \\
\text { burner }\end{array}$ & $20000-30000$ & $\begin{array}{l}\text { Induction } \\
\text { plate }\end{array}$ & 25000 & Microwave & $60000-185000$ & Fryer & 40000 \\
\hline Charcoal-stove & 2500 & $\begin{array}{l}\text { Hotplate+ } \\
\text { oven }\end{array}$ & 190000 & $\begin{array}{l}\text { Hotplate + } \\
\text { oven }\end{array}$ & 170000 & $\begin{array}{l}\text { Mini-oven }+ \\
\text { hotplate }\end{array}$ & $55000-75000$ & Kettle & $14000-50000$ \\
\hline & & & & $\begin{array}{l}\text { Handheld } \\
\text { water heater }\end{array}$ & 2500 & $\begin{array}{l}\text { Pail/bucket } \\
\text { heater }\end{array}$ & $10000-30000$ & $\begin{array}{l}\text { Household } \\
\text { geyser }\end{array}$ & 250000 \\
\hline
\end{tabular}




\section{B. Household level data collection}

\section{1) Participant and household background information}

Data collected from the participant and household background information section of the household surveys is summarised in Table $\mathrm{V}$ to provide context to the other findings. The samples represented the targeted socio-economic groups, with households from the urban sample most affluent (highest education levels and largest houses), and the peri-urban and rural samples less and least affluent respectively.

All respondents in the urban and peri-urban samples were connected to the national grid but have very frequent blackouts (5 times per week or more). These blackouts effect urban households' cooking the most, with the majority saying that blackouts often effect cooking, while the effect of blackouts on peri-urban households' cooking was smaller. Although, most of the rural respondents were connected to the recently installed mini-grid, this had not yet altered their cooking habits as none of the rural households were currently cooking using electricity.

TABLE V. BASIC INFORMATION BY SAMPLE AREA

\begin{tabular}{|l|c|c|c|}
\cline { 2 - 4 } \multicolumn{1}{c|}{} & \multicolumn{3}{c|}{ Sample location } \\
\hline $\begin{array}{l}\text { Characteristic } \\
\text { (median) }\end{array}$ & Form 3-4 & Form 1-2 & Std 5-8 \\
\hline $\begin{array}{l}\text { Rooms per } \\
\text { occupant }\end{array}$ & 0.91 & 0.70 & 0.55 \\
\hline $\begin{array}{l}\text { Wall } \\
\text { construction }\end{array}$ & $100 \%$ burnt brick + cement & $\begin{array}{c}89 \% \text { mud, } \\
11 \% \text { brick + cement }\end{array}$ \\
\hline $\begin{array}{l}\text { Roof } \\
\text { construction }\end{array}$ & \multicolumn{2}{|c|}{$100 \%$ metal sheets } & $\begin{array}{c}55 \% \text { metal, } \\
41 \% \text { grass }\end{array}$ \\
\hline $\begin{array}{l}\text { Electricity } \\
\text { connection }\end{array}$ & \multicolumn{2}{|c|}{$100 \%$ grid connected } & $\begin{array}{c}83 \% \text { connected to } \\
\text { mini-grid }\end{array}$ \\
\hline $\begin{array}{l}\text { Blackout } \\
\text { frequency }\end{array}$ & $100 \%$ “5 times per week or more" & $\begin{array}{c}100 \% \text { never have } \\
\text { blackouts }\end{array}$ \\
\hline $\begin{array}{l}\text { Do blackouts } \\
\text { effect cooking? }\end{array}$ & $\begin{array}{l}\text { Often (57\%) } \\
\text { Nevely (14\%) }\end{array}$ & $\begin{array}{c}\text { Often }(29 \%) \\
\text { Sometimes (7\%) } \\
\text { Never }(64 \%)\end{array}$ & N/A \\
\hline
\end{tabular}

Most households did not use sources of electricity other than the national grid, however a small number did use generators, solar home systems, pico-solar products and batteries.

\section{2) General cooking information}

\section{a) Cooking devices and fuels}

The differences in the use of hotplate type devices, by far the most popular type of cooking device in Malawi (where the use of ovens is very limited), are shown in Table VI; a hotplate is here defined as a device which heats the cooking pot or pan from below by burning fuel or heating element.

In urban households all but one respondent owned an electric hotplate $(93 \%)$ with one respondent owning only an LPG burner and oven. Urban households also often owned other electric cooking devices, including kettles (36\%), rice cookers (21\%), microwaves (14\%) and one owned an electric fryer. In peri-urban households, cooking device ownership was more mixed with charcoal stove ownership being the highest $(71 \%)$ followed by electric hotplates (57\%). Peri-urban households owned fewer other cooking devices than urban households, but some did own electric kettles $(50 \%)$ and one owned a microwave. All but one rural household cooked with firewood (97\%) while there was a small proportion who also owned a charcoal stove. There was no rural ownership of any other cooking devices.

TABLE VI. HOTPLATE TYPE DEVICE OWNERSHIP (BY LOCATION)

\begin{tabular}{|l|c|c|c|}
\cline { 2 - 4 } \multicolumn{1}{c|}{} & \multicolumn{3}{c|}{ Sample location } \\
\hline Hotplate fuel & Urban (14) & Peri-urban (14) & Rural (29) \\
\hline Firewood & 0 & $1 / 7 \%$ & $28 / 97 \%$ \\
\hline Charcoal & $2 / 14 \%$ & $10 / 71 \%$ & $5 / 17 \%$ \\
\hline Electric & $13 / 93 \%$ & $8 / 57 \%$ & 0 \\
\hline LPG & $3 / 21 \%$ & 0 & 0 \\
\hline
\end{tabular}

Fig. 2 shows a comparison between this study (prefixed by MECS) and similar data previously gathered by national censuses (prefixed by NSO) [6] [25], a study focussing on LPG (prefixed by PER) [7] and another on sustainable charcoal (prefixed by JICA) [26]. This validates the above findings, and demonstrates with more resolution the relationship between socio-economic factors and cooking practises in Malawi. Households which almost exclusively favour electricity as their main cooking fuel are in high income, urban areas, while cooking with firewood dominates in rural areas. Between these groups, both geographically and economically, charcoal is the most common fuel, but firewood and electricity are also favoured by many.

Fig. 2 also shows differences between targeted studies (MECS, PER and JICA) and national census data (NSO) demonstrating the diversity and inhomogeneity of cooking behaviour, particularly across Malawi's urban and peri-urban areas. Such variation is likely due to differences in the areas described as "urban" in the studies. MECS-urban, PER-urban and all the JICA samples specifically target affluent areas of the

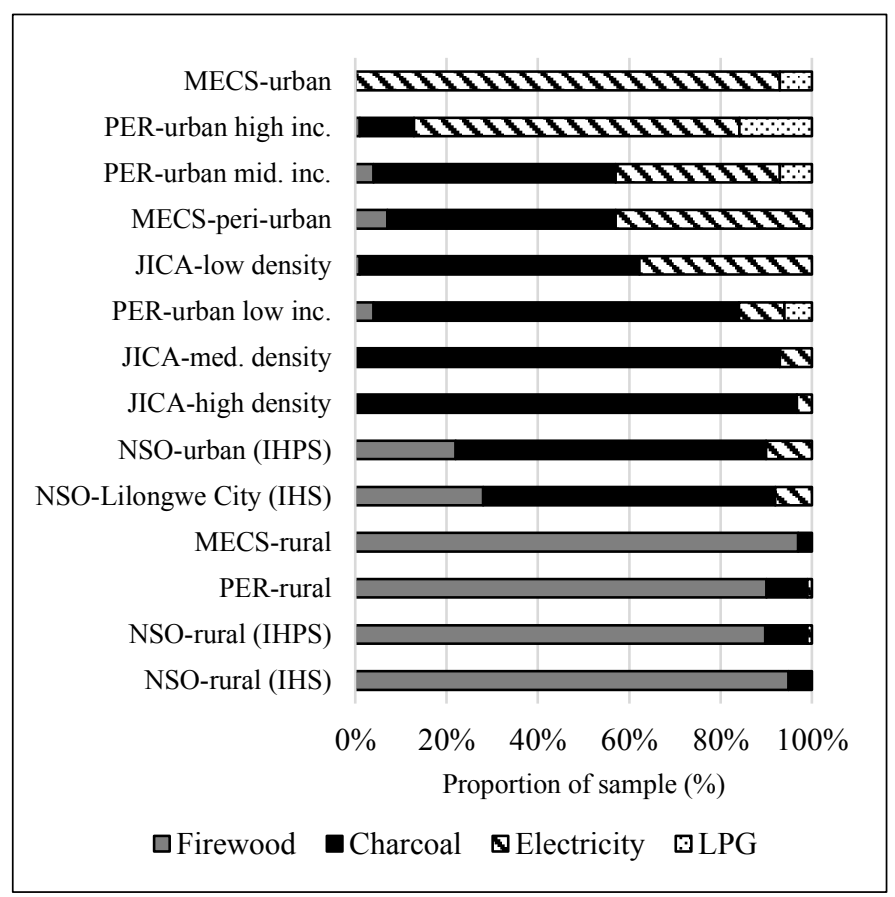

a MECS- "which of the listed devices do you own for cooking in your household?" (multiple responses) b NSO- "what is your main source of cooking fuel?" (single response only)

c PER- respondents ranked the fuels in order of preference (most preferred fuel quoted here)

d JICA- "which is your main source of energy for cooking? (single response only)

Fig. 2. Comparison of preferred cooking devices between four studies: $\mathrm{MECS}^{\mathrm{a}}, \mathrm{NSO}^{\mathrm{b}}$ [6] [25], PERFORM ${ }^{\mathrm{c}}$ [7] and $\mathrm{JICA}^{\mathrm{d}}$ [26] 
city of Lilongwe and do not include the surrounding, less urbanised areas, while NSO-Lilongwe City includes the entire district and NSO-urban also includes the district areas of Blantyre City, Mzuzu City and the Municipality of Zomba.

Reponses from experts to the online survey and interviews agreed that firewood was the main cooking fuel used in rural areas while responses varied in their account of cooking devices and fuels used in urban areas, demonstrating the complexity of urban cooking. Experts also highlighted that fuel stacking, defined as the use of multiple fuels by a single user or household (e.g. charcoal and electricity) [27] is a common and necessary practise. Reasons for this include the unreliable electricity supply, the affordability of different fuels and preferences about cooking certain foods on different devices.

\section{b) Cooking expenditure}

Reported cooking fuel expenditures are shown in Fig.3 grouped by sample area. Significant variation can be seen within the samples, likely due to the inaccuracy of self-reported expenditures, and the variation in cooking practises and socioeconomic characteristics. As such, the cooking expenditure data is indicative only, but provides some insight into differences between the sample areas.

Firewood (29 mainly rural users) was almost always gathered for free (93\%) with some gathering daily, weekly or monthly in varying quantities. Those who gathered monthly mentioned that they gather using a cart and store for use over a month. Charcoal (17 mainly peri-urban users) was bought in a variety of amounts usually either daily (24\% buy a small plastic bag at $300-500$ Malawi Kwacha (MWK)) or weekly/monthly $(65 \%$ buy a large "50kg" bag at 3,000-5,000 MWK, according to experts, a " $50 \mathrm{~kg}$ " bag contains around $12 \mathrm{~kg}$ of usable charcoal). Electricity was usually bought monthly or weekly at a wide range of different expenditures, likely due to differences in electrical appliance use and ownership. It was more common for peri-urban areas to buy electricity less often (78\% buy monthly) than urban areas $(38 \%$ buy monthly); possibly due to

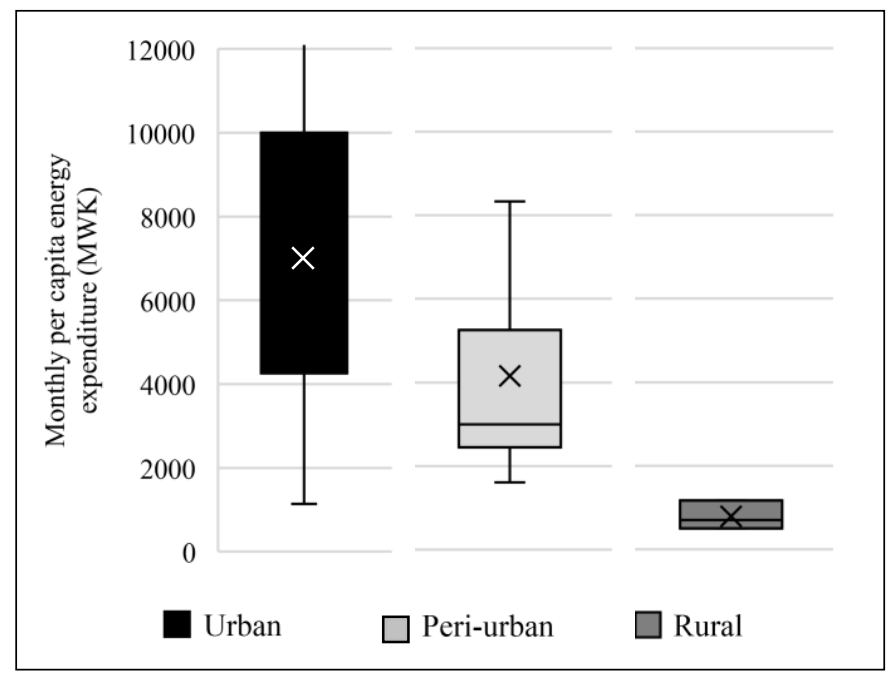

Fig. 3. Variation of monthly (per capita) cooking energy expenditures (MWK) for each sample area in this study higher electricity consumption levels in urban areas. Monthly purchases were usually between 10,000-30,000 MWK, and weekly purchases were usually between 2,000-10,000 MWK. LPG (three users, all urban) was bought far less regularly; responses ranged from "twice a month", to "after three months". The cost of LPG was 15,000 MWK for a $6 \mathrm{~kg}$ cylinder and 25,000 MWK for a $9 \mathrm{~kg}$ cylinder.

It was also possible to compare cooking expenditures from this study (MECS) with the PER and JICA data (see Fig. 4). It is shown that the urban sample in this study could be more specifically referred to as "urban, high income" whilst peri-urban could also be referred to as "urban, low-middle income".

Comparison of expenditure by fuel indicated that in urban areas cooking with electricity-only appears to be the cheapest option, however this finding is based on averages over very small sample sizes. Cooking with electricity-only cost on average 6,571 MWK per capita/month (9 households), compared with cooking on electricity and charcoal which cost 7,525 MWK per capita/month (2 households) and cooking on electricity and LPG which cost 8,129 MWK per capita/month (3 households).

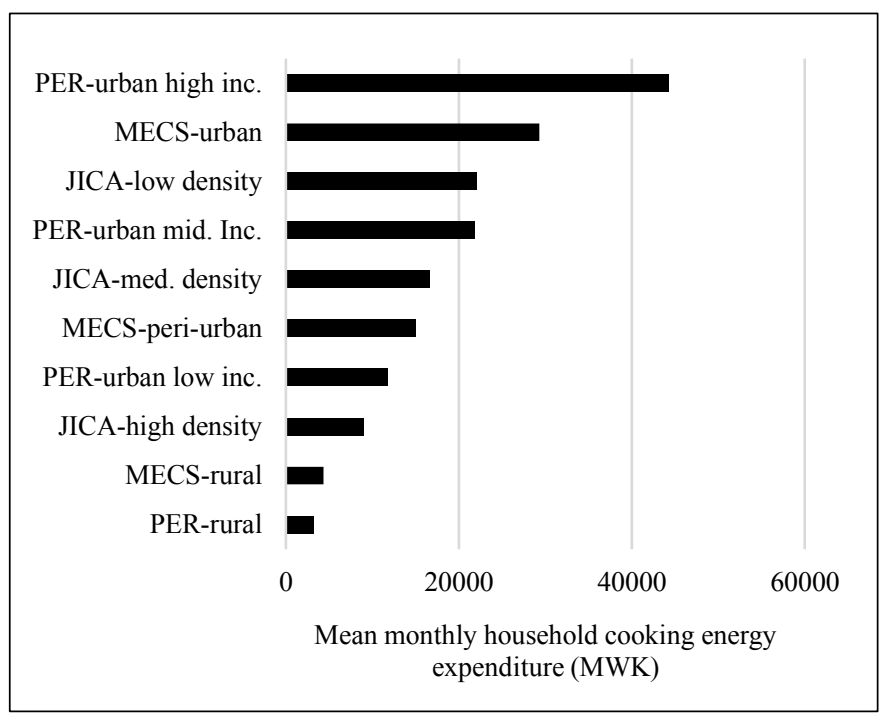

Fig. 4. Comparison of monthly household cooking expenditures between three studies: MECS, PERFORM [7] and JICA [26].

\section{3) Indicative cooking diaries}

\section{a) Meals}

Indicative cooking diaries showed that while rural areas always do some form of cooking activity for all meals, urban and peri-urban areas do not cook lunch approximately a third of the time, and sometimes do not cook dinner (see Table VII). This is likely to be caused in part by urban and peri-urban cooking being affected by blackouts. $67 \%$ of those in urban and peri-urban areas who do not cook all meals said that blackouts effect cooking, while only $30 \%$ of those who do cook all meals said that blackouts effect cooking. Experts also highlighted that lunch in particular was less likely to be cooked in urban areas, due to people buying lunch while at work. It was also said that in urban areas people would generally be more likely to eat out. 
TABLE VII. LIKELIHOOD OF A MEAL BEING COOKED ON A WEEKDAY OR WEEKEND DAY BY SAMPLE AREA [URBAN: 14, PERI-URBAN: 14, RURAL: 29]

\begin{tabular}{|l|c|c|}
\multicolumn{1}{c}{} & \multicolumn{2}{c}{ Breakfast } \\
\cline { 2 - 3 } \multicolumn{1}{c|}{} & $\begin{array}{c}\text { Week } \\
\text { day }\end{array}$ & $\begin{array}{c}\text { Week } \\
\text { end }\end{array}$ \\
\hline Urban & $86 \%$ & $79 \%$ \\
\hline Peri & $93 \%$ & $100 \%$ \\
\hline Rural & $100 \%$ & $100 \%$ \\
\hline
\end{tabular}

Lunch
\begin{tabular}{|c|c|}
\hline $\begin{array}{c}\text { Week } \\
\text { day }\end{array}$ & $\begin{array}{c}\text { Week } \\
\text { end }\end{array}$ \\
\hline $71 \%$ & $57 \%$ \\
\hline $64 \%$ & $64 \%$ \\
\hline $100 \%$ & $100 \%$ \\
\hline
\end{tabular}

Dinner
\begin{tabular}{|c|c|}
\hline $\begin{array}{c}\text { Week } \\
\text { day }\end{array}$ & $\begin{array}{c}\text { Week } \\
\text { end }\end{array}$ \\
\hline $100 \%$ & $71 \%$ \\
$100 \%$ & $93 \%$ \\
$100 \%$ & $100 \%$ \\
\hline
\end{tabular}

\section{b) Dishes}

Indicative diaries showed that meals in urban, peri-urban and rural areas are commonly made up from 10 core dishes (see Table VIII) which constitute $90 \%$ of all the dishes mentioned. Modern cooking devices would need to be proven appropriate for cooking these dishes in Malawian contexts (at a minimum) in order to be successful at a large scale.

\section{TABLE VIII. CORE DISHES}

\begin{tabular}{|l|l|}
\hline \multicolumn{2}{|c|}{ Breakfast } \\
\hline Tea/Coffee & Eggs \\
\hline Porridge & Breakfast \\
\hline Potatoes & Tea/Coffee \\
\hline
\end{tabular}

\begin{tabular}{|l|l|}
\hline \multicolumn{2}{|c|}{ Lunch/Dinner } \\
\hline Nsima/rice & Fish \\
\hline Beans & Eggs \\
\hline Vegetables & Meat/poultry \\
\hline
\end{tabular}

These core dishes are almost always cooked by boiling $(88 \%$ of the time) while meat/poultry, fish, eggs and potatoes are also sometimes deep fried ( $10 \%$ of the time) or shallow fried $(2 \%$ of the time). Another key finding was that beans, considered a staple for most East African countries and which usually require large amounts of fuel to cook for long periods, were cooked for just $13 \%$ of lunches and $9 \%$ of dinners across the three samples.

There were also differences in which dishes were usually cooked for each meal by the rural sample compared with the urban and peri-urban samples (Table IX). In rural areas, eggs were never cooked for breakfast, while they were cooked for breakfast $25 \%$ and $21 \%$ of the time in urban and peri-urban areas respectively. Also, nsima (a type of porridge, dough-like in consistency, made from maize flour also known as ugali in other African countries) was cooked for almost all lunches and dinners in rural areas (95\% of the time) while it was cooked less often for lunch and dinner in urban (46\% and $71 \%)$ and peri-urban areas (61\% and $79 \%)$. Cooking meat was also less common in rural areas, cooked for $17 \%$ of lunches and dinners compared with $54 \%$ in urban and $45 \%$ in peri-urban areas.

TABLE IX. DISH POPULARITY [URBAN:28, PERI-URBAN:28, RURAL:58]

\begin{tabular}{|c|c|c|c|c|c|c|}
\hline & \multicolumn{4}{|l|}{ Breakfast } & & \\
\hline & Tea/coffee & Porridge & Potatoes & Eggs & & \\
\hline Urban & $79 \%$ & $21 \%$ & $39 \%$ & $25 \%$ & & \\
\hline Peri & $89 \%$ & $18 \%$ & $36 \%$ & $21 \%$ & & \\
\hline \multirow[t]{3}{*}{ Rural } & $55 \%$ & $34 \%$ & $24 \%$ & $0 \%$ & & \\
\hline & \multicolumn{6}{|l|}{ Lunch } \\
\hline & Nsima/rice & Beans & Vegetables & Fish & Eggs & Meat/poultry \\
\hline Urban & $46 \%$ & $11 \%$ & $36 \%$ & $18 \%$ & $4 \%$ & $36 \%$ \\
\hline Peri & $61 \%$ & $0 \%$ & $32 \%$ & $11 \%$ & $4 \%$ & $46 \%$ \\
\hline \multirow[t]{3}{*}{ Rural } & $95 \%$ & $29 \%$ & $55 \%$ & $9 \%$ & $10 \%$ & $19 \%$ \\
\hline & \multicolumn{6}{|l|}{ Dinner } \\
\hline & Nsima/rice & Beans & Vegetables & Fish & Eggs & Meat/poultry \\
\hline Urban & $71 \%$ & $0 \%$ & $46 \%$ & $7 \%$ & $0 \%$ & $71 \%$ \\
\hline Peri & $79 \%$ & $11 \%$ & $46 \%$ & $25 \%$ & $7 \%$ & $43 \%$ \\
\hline Rural & $95 \%$ & $17 \%$ & $50 \%$ & $5 \%$ & $22 \%$ & $14 \%$ \\
\hline
\end{tabular}

\section{c) Cooking device selection}

The indicative diaries confirmed that the urban sample cooked mostly with electricity $(86 \%-100 \%$ of dishes for each meal used an electrical appliance), while the peri-urban sample cooked using a mixture of charcoal (28-70\% of dishes) and electricity (30-67\% of dishes), and the rural sample used predominantly firewood ( $88 \%-100 \%$ of dishes for each meal).

Table $\mathrm{X}$ shows the proportion of those who cook a dish with a device, out of those who cook that dish and own the device (i.e. a low percentage corresponds to a small proportion of those who own the device choosing to cook that dish with it). Charcoal is clearly chosen less often than other devices, indicating that Malawians prefer to cook with other fuels.

TABLE X. PROPORTION OF RESPONDENTS WHO OWN A DEVICE WHICH CHOOSE TO COOK WITH IT [ALL LOCATIONS AGGREGATED]

\begin{tabular}{|l|c|c|c|c|c|}
\multicolumn{1}{c|}{ Breakfast } \\
\cline { 2 - 6 } \multicolumn{1}{c|}{} & $\#$ & $\begin{array}{c}\text { Firewood } \\
\text { 3 stone }\end{array}$ & $\begin{array}{c}\text { Charcoal - } \\
\text { stove }\end{array}$ & $\begin{array}{c}\text { Electric - } \\
\text { hotplate }\end{array}$ & $\begin{array}{c}\text { Electric - } \\
\text { kettle }\end{array}$ \\
\hline Tea/Coffee & 79 & $100 \%$ & $30 \%$ & $53 \%$ & $95 \%$ \\
\hline Porridge & 31 & $100 \%$ & $63 \%$ & $86 \%$ & N/A \\
\hline Potatoes & 35 & $100 \%$ & $50 \%$ & $87 \%$ & N/A \\
\hline Eggs & 13 & $*$ & $50 \%$ & $100 \%$ & N/A \\
\hline
\end{tabular}

\begin{tabular}{|l|c|c|c|c|}
\multicolumn{1}{c|}{ Lunch/Dinner } \\
\cline { 2 - 3 } \multicolumn{1}{c|}{} & $\begin{array}{c}\text { Firewood - } \\
\text { 3 stone }\end{array}$ & $\begin{array}{c}\text { Charcoal - } \\
\text { stove }\end{array}$ & $\begin{array}{c}\text { Electric - } \\
\text { hotplate }\end{array}$ \\
\hline Nsima/rice & 139 & $100 \%$ & $46 \%$ & $86 \%$ \\
\hline Beans & 30 & $96 \%$ & $38 \%$ & $*$ \\
\hline Vegetables & 84 & $100 \%$ & $67 \%$ & $97 \%$ \\
\hline Fish & 22 & $100 \%$ & $80 \%$ & $82 \%$ \\
\hline Eggs & 12 & $100 \%$ & $50 \%$ & $*$ \\
\hline Meat/poultry & 54 & $100 \%$ & $43 \%$ & $93 \%$ \\
\hline
\end{tabular}

\section{4) Focus group discussion}

The focus group held in the rural area generated and ranked positive and negative aspects associated with firewood and also charcoal (shown in Table XI).

TABLE XI. POSITIVE AND NEGATIVE ASPECTS OF COOKING WITH FIREWOOD AND COOKING WITH CHARCOAL

Firewood

\begin{tabular}{|l|l|}
\hline \multicolumn{1}{|c|}{ Positive aspects } & \multicolumn{1}{c|}{ Negative aspects } \\
\hline 1. Cooks fast & 1. Costs money \\
2. Can also use manure as fuel & 2. Smoke causes illness, dirties walls \\
3. Freely collected & 3. Makes pots dirty \\
4. Easy to start the fire & 4. Burns food when there is too \\
5. Can be used to brew local beer & \multicolumn{1}{c|}{ much fire } \\
\hline
\end{tabular}

Charcoal

\begin{tabular}{|l|l|}
\hline \multicolumn{1}{|c|}{ Positive aspects } & \multicolumn{1}{c|}{ Negative aspects (unranked) } \\
\hline 1. Not too much smoke & Deforestation \\
2. Doesn't make pots dirty & Health issues because of smoke \\
3. Can be used for space heating & Slow to start the fire \\
4. Easier to use in rainy season & Expensive \\
5. Fast to cook (once fire is started) & \\
\hline
\end{tabular}

Focus group participants also highlighted other challenges associated specifically with gathering firewood. Firstly, the time spent gathering firewood, said to be between 1.5 and 3 hours on each occasion, varied due to there being inconsistent availability of good quality, dry firewood. This was exacerbated in the rainy season, when collecting firewood becomes hazardous due to slippery ground and cold, wet conditions which increase the 
chances of getting ill. In more extreme cases, due to the forest being a protected area, those caught collecting firewood have previously been detained and severely punished.

\section{DISCUSSION}

This market assessment for modern cooking in Malawi has begun to uncover the complexity and diversity of household cooking practises in Malawi. Household cooking data collected by this study's surveys, particularly the indicative cooking diaries, has provided insight into what, how, and with what foods are cooked in Malawian households and is, to the authors' knowledge, the first of its kind and depth in Malawi. Survey findings have been validated by comparisons with other studies and combined with the findings from interviews with in-country experts to identify the barriers and opportunities for a scaled-up transition towards modern cooking in Malawi.

Firewood is the dominant fuel in rural areas with most households gathering it for free. Affluent households in urban areas cook mostly with electricity (some supplementing with charcoal and or LPG), and usually spend 4,000-10,000 MWK per capita per month on cooking energy. In less affluent and periurban areas, households use a combination of charcoal and electricity, spending 2,000-6,000 MWK per capita per month.

However, that is not to say that cooking with electricity is more expensive than cooking with charcoal. When comparing between households within the urban sample only, the data indicated that it is cheaper on average to cook with electricityonly than with charcoal and electricity, while it was most expensive to cook with electricity and LPG. Experts concurred that there is recent evidence that electricity is the cheapest cooking fuel in grid connected areas of Malawi (excluding freely gathered firewood). However, larger and more numerous samples would be needed to statistically confirm and quantify these differences, and to better understand the diversity of cooking practises across urban and peri-urban areas.

By far the most significant barrier to electric cooking is Malawi's unreliable national grid, which largely serves urban areas only. However, despite this, as many as $90 \%$ of households in affluent, urban areas use electricity as their main source of cooking energy. As such, the factors effecting cooking behaviour, and techniques used to mitigate the effects of blackouts on cooking also need to be investigated in more detail.

Cooking with electricity is also considered expensive by some Malawians, particularly for long-cook foods such as beans, and the cost of electric cooking devices is much higher than for biomass stoves. The most basic hotplate costs at least three times as much as a charcoal stove, with lower priced devices said to be of questionable quality. More efficient, low powered devices such as rice cookers and electric pressure cookers (which may have the potential to be used even on weak electricity grids [28]) are available, but consumer awareness is very limited, and prices are high meaning they are currently only accessible to mid-high income households. In fact, even the most basic energy-saving cooking techniques, e.g. soaking dried foods before cooking and using lids while boiling, are not widely practised. Such simple techniques, alongside others including finely chopping ingredients and using minimum amounts of water have been shown to cook long-cook dishes in as little as a third of the time, and a tenth of the usual cost of cooking [29].

Cooking with LPG, as well as being more expensive than cooking with charcoal or electricity, is widely considered dangerous by those in all areas of society. In addition, there is a severe lack of LPG infrastructure, meaning replenishing fuel is inconvenient in urban areas where Malawi's small number of refilling stations are located, and difficult or impossible in rural areas. In fact, due to Malawi's poor road conditions beyond its main arteries, rural areas are likely to remain unserved by LPG distribution for the foreseeable future. Furthermore, LPG must currently be paid for in large lump sum payments (e.g. 15,000 MWK for $6 \mathrm{~kg}$ ) which are unaffordable for all but the most affluent in society (most buy charcoal in small bags for 300-500 MWK or large bags for 3,000-5,000 MWK).

However, should some of these barriers be overcome, it appears that there is a latent demand for modern cooking. In fact, several experts mentioned that before load shedding became the norm, electric cooking was growing in popularity in grid connected areas, a positive sentiment echoed by older studies [9]. Also, indicative diary data showed that given the option, cooks preferred to cook with electricity over charcoal.

In addition, comments by experts and findings from the focus group demonstrated that biomass is far from a desirable cooking fuel. Negative aspects highlighted were that: charcoal smoke is dirty (for clothes/homes) and bad for health; the time taken to start a charcoal fire is inconvenient; and the temperature cannot easily be controlled. Similar aspects were mentioned in relation to firewood, alongside challenges specific to its use during the rainy season (damp wood and cold, slippery conditions when gathering) and particular difficulties when living near protected forests. Comparing these biomass cooking experiences with modern cooking demonstrates its potential; electric or LPG devices reliably provide instant, controllable heat and are smokeless. However, modern cooking devices' versatility, speed of cooking and most importantly their ability to cook Malawian dishes in ways which are acceptable to Malawian people all need to be tested and proven by Malawians, particularly in the case of non-conventional devices such as rice cookers and electric pressure cookers. Through the collection of indicative cooking diaries, this study has shown that the majority of the household menu in Malawi is constituted by 10 core dishes which should be the basis of such testing.

Given the knowledge gathered throughout this study, an outline roadmap for modern cooking in Malawi is offered.

In the immediate-short term, already well-developed efforts to propagate improved biomass stoves should continue and could be supplemented by increased efforts to encourage more efficient cooking techniques. During the same period, the scale-up of modern cooking is most appropriate through encouraging LPG use in urban areas, as the reliability of Malawi's national grid is unlikely to improve until large electrical infrastructure projects such as Mozambique-Malawi Regional Interconnector [30] are completed. The numerous barriers to the scale up of LPG cooking in Malawi could be reduced by improving public awareness, delivery strategies and supply chains, and through subsidies or new payment models to improve affordability. 
In the short-medium term, there is the potential to scale up electric cooking in urban areas and on mini-grids. Many highincome households in urban areas already use electricity as their main source of cooking energy, while more would be likely to transition as a result of public awareness campaigns around the economic benefits of cooking with electricity and a reduction in the cost of devices. Importantly, should the reliability of Malawi's national grid improve, the latent demand for electric cooking represents a significant opportunity for a transition to modern cooking in grid-connected areas. Mini-grids are the ideal vehicle for effecting a transition to modern cooking in rural areas (their ability to improve electricity access in Malawi is already recognised [14]) but deployment is likely to be slow. Also, several knowledge gaps need to be overcome, including minigrids' ability to support the electrical demand of the use of electric cooking devices and the affordability of cooking on mini-grid tariffs.

However, this is likely to be a non-binary, inhomogeneous process, with some households and businesses finding a use for a variety of different cooking fuels and devices. As such, the spread of modern cooking must be seen as a process of "cleaning the cooking stack", gradually reducing the amount of biomass use through more efficient, modern cooking practices. Alongside technical and economic investigations of LPG and electric cooking, further study is needed to understand the applicability of modern cooking devices to the Malawian context, particularly those uncommon and unconventional to Malawi such as rice cookers and electric pressure cookers.

\section{CONCLUSION}

This market assessment for modern cooking in Malawi has provided insight into what, how, and with what, dishes are cooked in Malawian households, and perspectives on the sector from in-country experts. As such, the diversity of cooking practises, and barriers and opportunities for a scaled-up transition towards modern cooking have been presented.

Malawi's modern cooking sector is small and is mainly constituted by the small proportion of households which are connected to the national grid and can afford electric cooking devices. Cooks are unsatisfied by the status quo, cooking with biomass, and there is a latent demand for modernising cooking. Options are restricted by a number of significant barriers, including the unreliable electricity supply, high costs of modern cooking devices, and lack of development of the LPG sector. Given the strong drivers for reducing biomass use, the findings of this study are important for directing policies and interventions around modern cooking and in demonstrating the potential for investment in the growth of the sector in Malawi.

Urban areas and mini-grids demonstrate the most potential for a scale-up of modern cooking, but both contexts require further study to better understand the diversity of urban and periurban cooking practises and to the incumbent power systems' ability to support electric cooking.

\section{ACKNOWLEDGMENTS}

The authors gratefully acknowledge the funding support provided by UKAid through the MECS programme.

\section{REFERENCES}

[1] IEA, UN Statistics Division, The World Bank, and WHO, "The Energy Progress Report," p. 176, 2019, [Online]. https://trackingsdg7.esmap.org/.

[2] S. Batchelor, E. Brown, N. Scott, and J. Leary, "Two Birds, One StoneReframing Cooking Energy Policies in Africa and Asia," Energies, vol. 12, no. 9, p. 1591, Apr. 2019.

[3] WHO, "Household air pollution and health," 2018. https://www.who.int/en/news-room/fact-sheets/detail/household-airpollution-and-health (accessed Apr. 21, 2020).

[4] United Nations, "National Accounts-Analysis of Main Aggregates." https://unstats.un.org/unsd/snaama/index (accessed Apr. 21, 2020).

[5] The World Bank, "The World Bank - Data - Malawi," 2016. https://data.worldbank.org/country/malawi (accessed Apr. 08, 2019).

[6] Malawi National Statistical Office, "Integrated Household Survey 20162017," no. November, p. 208, 2017, http://www.nsomalawi.mw/.

[7] Practical Action Consulting, "Qualitative and quantitative research on LPG in Malawi," no. November, 2018, http://conrema.org/downloads/.

[8] United Nations, "Feasibility study for the use of ethanol as a household cooking fuel in Malawi," no. November, p. 73, 2007.

[9] K. O'Sullivan and K. Fitzgerald, "Household Energy Use in Malawi," pp. 1-47, 2006, [Online]. http://documents.worldbank.org/curated/en/214711 468056950074/pdf/705580ESW0P08001d0Energy0Use0Malawi.pdf.

[10] Gold Standard, "Cleaner and Safer Stoves", https://www.goldstandard .org/projects/cleaner-and-safer-stoves-malawi (accessed Apr. 22, 2020).

[11] Government of Malawi, "National Energy Policy." 2018.

[12]Department of Energy Affairs, "Cooking \& Heating Energy." https://www.energy.gov.mw/index.php/services/promotion-of-alternativeenergy/liquid-fuels-gas/cooking-heating-energy (accessed Apr. 21, 2020).

[13] Ministry of Natural Resources Energy and Mining, "National Charcoal Strategy 2017-2027.”.

[14]Malawi Energy Regulatory Authority, "Malawi Renewable Energy Strategy." 2017.

[15]MECS, "Modern Energy Cooking Services." https://www.mecs.org.uk/ (accessed Apr. 21, 2020).

[16]MECS, "Tanzania." http://www.mecs.org.uk/download-category/tanzania/ (accessed Apr. 21, 2020).

[17]MECS, "Zambia." http://www.mecs.org.uk/download-category/zambia/ (accessed Apr. 21, 2020).

[18]R. Bailis, "Kitchen Performance Test 4.0," 2018. Accessed: Apr. 22, 2020, https://www.cleancookingalliance.org/technology-andfuels/testing/protocols.html.

[19]L. Stevens, E. Santangelo, K. Muzee, M. Clifford, and S. Jewitt, "Market mapping for improved cookstoves: barriers... in East Africa," Dev. Pract., vol. 30, no. 1, pp. 37-51, Jan. 2020, Accessed: Apr. 22, 2020.

[20]"National Cookstove Steering Committee." http://www.mbaula.org/about /national-cookstove-steering-committee/ (accessed May 01, 2020).

[21]J. Leary, S. Batchelor, and N. Scott, "Cooking Diaries 3.0 Protocols," no. August, pp. 1-54, 2019, https://www.mecs.org.uk/wp-content/uploads/ 2019/09/Cooking-Diaries-3.0-Protocols-JL-9-9-19-LOW-RES.pdf.

[22]W. Coley, D. Frame, and A. Eales, "Microgrid baselining - Summary of findings." https://ease.eee.strath.ac.uk/ (accessed Apr. 22, 2020).

[23] "KoBoToolbox | Data Collection Tools for Challenging Environments." https://www.kobotoolbox.org/ (accessed Apr. 30, 2020).

[24] Tetra Tech, "Protecting Ecosystems and Restoring Forests in Malawi." https://www.tetratech.com/en/projects/protecting-ecosystems-andrestoring-forests-in-malawi (accessed Apr. 24, 2020).

[25] Malawi National Statistical Office, "Integrated Household Panel Survey 2016," 2017, Web-link unavailable.

[26]K. Wiyo, "Survey on Consumer Preferences on The Use of Sustainable Charcoal from COSMA-DFR," 2019, Web-link unavailable

[27]B. Van Der Kroon, R. Brouwer, and P. J. H. Van Beukering, "The energy ladder: Theoretical myth or empirical truth?" Renewable and Sustainable Energy Reviews, vol. 20. Elsevier Ltd, pp. 504-513, Apr. 01, 2013.

[28]J. Fodio Todd and J. Leary, "Eating through power cuts with EPCs." https://www.mecs.org.uk/blog/ (accessed May 01, 2020).

[29]J. Leary and J. Fodio Todd, "The Kenya eCookBook Beans \& Cereals Edition," pp. 1-80, 2019, https://www.mecs.org.uk/ecookbook/.

[30]Department of Energy Affairs, "Malawi-Mozambique Regional Interconnector." https://energy.gov.mw/index.php/projects/interconnect ion-projects/malawi-mozambique-regional-interconnector (accessed May 01, 2020). 